Case report

OPen Access

CrossMark

\title{
Giant aneurysmal dermatofibroma: a case of the rare variant of dermatofibroma
}

\begin{abstract}
Dermatofibroma is a benign skin tumor that may have a rare aneurysmal histological variant, aneurysmal dermatofibroma (AD). The diagnosis is by histological evaluation, which shows vascular spaces that dissect the tumor stroma, forming in some cases true venous lakes. However, AD is usually less than $20 \mathrm{~mm}$ in diameter. We describe the case of a female patient whit a $45 \mathrm{~mm}$ tumor in her right leg.
\end{abstract}

Keywords: dermatofibroma, neoplasm, skin, soft tissue tumors, hemosiderin, leg
Volume 3 Issue $6-2019$

\author{
Rogério Nabor Kondo,' Lívia Álvares \\ Ramires, ${ }^{2}$ Fernanda Barrancos Liberatti, ${ }^{3}$ \\ Angela Navarro Gordan ${ }^{4}$ \\ 'Dermatologist, State University of Londrina , Brazil \\ ${ }^{2}$ Medical Student, University of Vale do Itajaí (Univali), Brazil \\ ${ }^{3}$ Medical Student of Positivo University, Brazil \\ ${ }^{4}$ Pathologist, Private laboratory, Brazil
}

Correspondence: Rogério Nabor Kondo, Dermatologist, Assistant professor of dermatology of Hospital, Universitário Regional do Norte do Paraná, State University of Londrina, Brazil, Email kondo.dermato@gmail.com

Received: December 14,2019 | Published: December 23, 2019

\section{Introduction}

Dermatofibroma or benign fibrous histiocytoma is a common benign skin neoplasia, ${ }^{1}$ but the aneurysmal variant of dermatofibroma called aneurysmatic dermatofibroma (AD) is a seldom cutaneous neoplasm (less than 2\%). ${ }^{2}$ However, giant AD cases (larger than 20 $\mathrm{mm})$ are more rare, ${ }^{2}$ as in the present case.

The purpose of the case report is to describe this special dermatofibroma sutype, rarely mentioned in the literature and its importance in the differencial diagnosis in relation to others types of tumors.

\section{Case report}

A 26-year-old female patient with a history of asymptomatic purpuric nodule in the anterolateral region of the right leg for 5 years. It began as ingrown hair. She had already performed hypertonic glucose for lower limb varicose veins, but none previous treatment had been done to tumor.

Dermatological examination revealed a nodule with a purpuric center of fibroelastic consistency, measuring approximately $45 \times 35 \mathrm{~mm}$, in the anterolateral region of the right leg (Figure 1). The left inguinal lymph nodes were not enlarged.

Excisional nodule biopsy was performed for diagnosis. Panoramic photo of the microscopic slide shows the aneurysmal aspect of the lesion. It also shows cell proliferation in the more basophilic dermis with vascular spaces. A histopathology showed typical areas of dermatofibroma interspersed with foamy histiocytes, hemosiderin, and spaces that red blood cell without endothelial lining (Figure 2 \& 3).

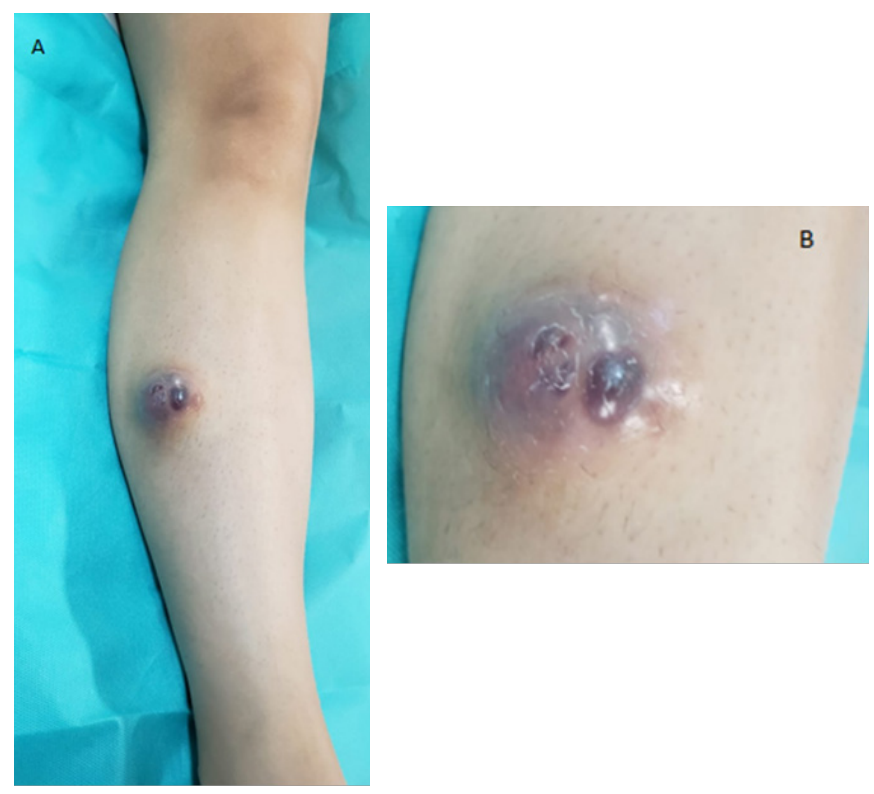

Figure I A: Purpuric lesion on the right leg. B:Detail of the lesion.

Immunohistochemistry (IH) showed CD34 negativity, ruling out vascular proliferation. Five months later surgical treatment, the patient was able to walk without pain. She complained of discrete local paresthesia. 


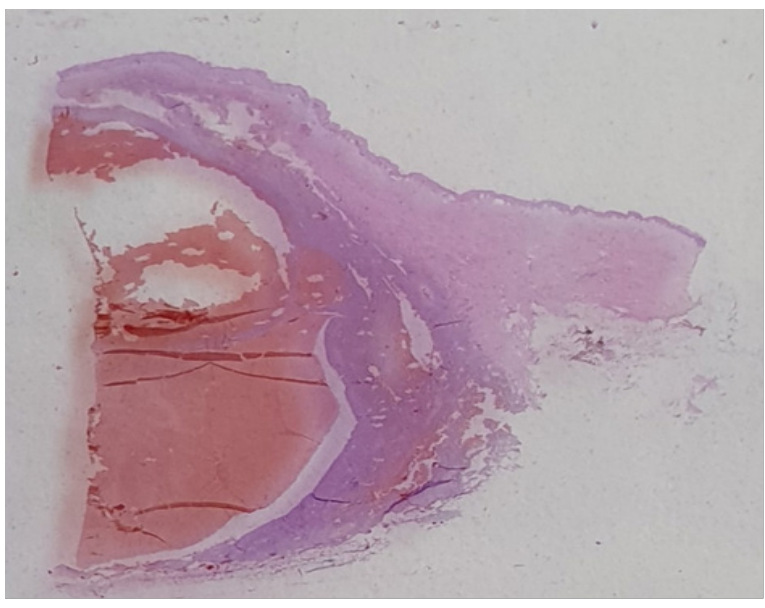

Figure 2 Panoramic photo shows the aneurysmal aspect of the lesion, with cell proliferation of the dermis and vascular spaces.

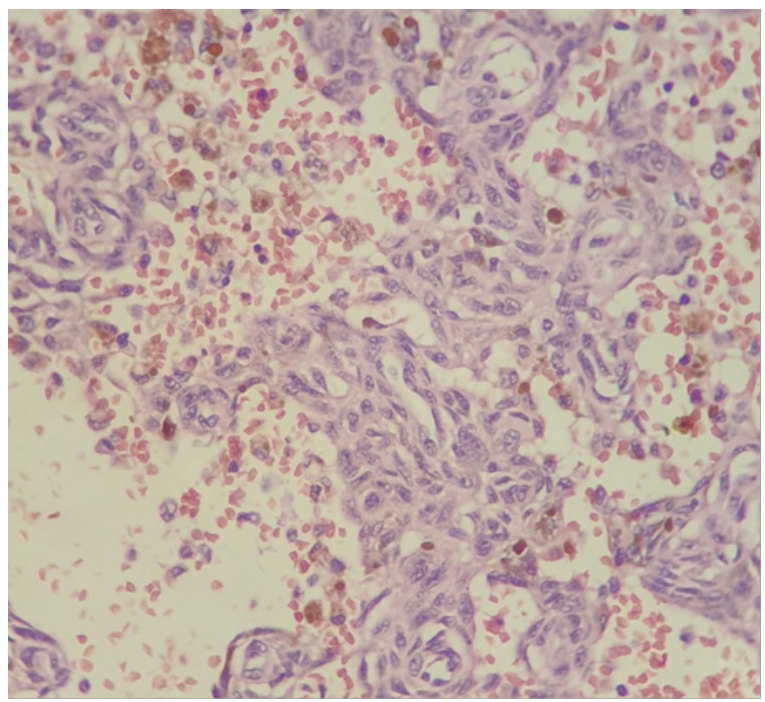

Figure 3 Microscopic examination. Typical areas of dermatofibroma interspersed with foamy histiocytes, hemosiderin, and spaces that red blood cell without endothelial lining.

\section{Discussion}

Dermatofibroma or benign fibrous histiocytoma is a benign neoplasia first described by Stout and Lattes in $1967 .{ }^{1}$ The aneurysmal variant of dermatofibroma was observed by Gross and Walbach in 1943, in which they discussed the relationship between it and sclerosing hemangioma. In 1966, Ariston and Reed described lesions that consisted of typical dermatofibroma areas interspersed with foamy histiocytes, hemosiderin, and spaces filled with red blood cells without endothelial lining. In 1981, Santa Cruz and Kyriakos named three of a series of 17 cases "aneurysmal fibrous histiocytoma", also called aneurysmal dermatofibroma (AD). ${ }^{2}$

The diagnosis of $\mathrm{AD}$ is established by histopathological findings. ${ }^{2-7}$ Dermal localized neoformation consists of myofibroblasts, spindle cells and hemosiderin-containing histiocytes in their fibrous stroma, Touton-type multinucleated giant cells, and "unendothelial" blood spaces occupying the most of the injury. ${ }^{2}$
Therefore, as these vascular spaces are not endothelial lined and are not abnormal dilations of the vascular system, it would be incorrect to use the term "aneurysmal". In addition, there is no vascular proliferation in $\mathrm{AD}$, which makes the term "angiomatoid" incorrect as well. ${ }^{2}$

From an immunohistochemical point of view, dermatofibroma spindle cells have smooth muscle actin reactivity and CD57 show fibroblast and myofibroblast differentiation, being negative for factor VIII, desmin, CD34 and protein S-100, ${ }^{2}$ just as in the present case.

The etiology of $\mathrm{AD}$ is not very clear. For some authors this phenomenon could occur in areas of hypocellularity or secondarily to repeated trauma or microtrauma that would precipitate microhemorrhages. ${ }^{2}$ The patient in the case had a history of varicose vein glucose applications at the site.

AD usually presents with a single nodular lesion, $5 \mathrm{~mm}$ to $20 \mathrm{~mm}$, brownish, dark red or black in color. ${ }^{2,4}$ The present case showed a $45 \mathrm{~mm}$ lesion (giant $\mathrm{AD}$ ), twice the size of the described variations. that, at first, suspicions of malignant tumors may be raised.

Differential diagnosis is established with benign vascular lesions such as hemosiderodic hemangioma and some malignant vascular lesions such as angiomatoid malignant fibrous histiocytoma (which affects the subcutaneous cell tissue, muscle and periosteum) and melanoma, whose histological aspects are totally different. Other differential clinical diagnoses include papular, nodular or plaque lesions of Kaposi's sarcoma (CD4 immunoreactive and absence of fibrohistiocytic cells). ${ }^{2}$

Treatment of choice is surgical resection..$^{2-6}$ Surgical margin of at least 3 to $5 \mathrm{~mm}$ is advised.2 According to some studies, the recurrence rate has been shown to be about $20 \%$, and the clinical follow-up of patients. ${ }^{2,7}$

\section{Conclusion}

$\mathrm{AD}$ is a seldom variant of dermatofibroma and it has differencial diagnosis with others important types of tumor. The surgical resection is the treatment of choice.

\section{Conflict of interest}

The authors report no conflicts of interest.

\section{Acknowledgments}

None.

\section{Financial fuding}

None.

\section{References}

1. Lee YB, Cho BK, Park HJ, et al. Dermatofibroma on the nipple: A rare and interesting case. J Am Acad Dernatol. 2012;66(4):AB48.

2. Pegas JR, Santos BA, Prado IDF, et al. Dermatofibroma aneurismático. Surg Cosmet Dermatol. 2010;2(2):225-227.

3. Liu S, Lozeau D. Giant aneurysmal benign fibrous histiocytoma (dermatofibroma). J Cutan Pathol. 2018;45(10):774-776.

4. Kawakami Y, Oyama N, Nishibu A, et al. A case of 'giant' aneurysmal benign fibrous histiocytoma. Clin Exp Dermatol. 2006;31(3):456-457. 
5. Serin M, Leblebici C, Aksu EK, et al. Aneurysmal fibrous histiocytoma. BMJ Case Rep. 2018;2018.

6. Franco NG, González GM, Chicas EE. Dermatofibroma aneurismático. Dermatologia Rev Mex. 2007;51(3):117-120.
7. Antony A, Kiran CM, Phansalkar M, et al. Aneurysmal Variant of Fibrous Histiocytoma. A Rare Entity Known for Recurrence. J Clin Diagn Res. 2017;11(6):ED08-ED09. 